\title{
Comparison of two personal ultraviolet index monitors for sun awareness in South Africa
}

AUTHORS:

Caradee Y. Wright ${ }^{1}$

Patricia N. Albers ${ }^{2}$

\section{AFFILIATIONS:}

${ }^{1}$ Climate Studies, Modelling and Environmental Health Research Group, Council for Scientific and Industrial Research, Pretoria,

South Africa

${ }^{2}$ Environment and Health Research Unit, Medical Research Council. Johannesburg, South Africa

\section{CORRESPONDENCE TO: Caradee Wright}

\section{EMAIL:}

cwright@csir.co.za

\section{POSTAL ADDRESS:}

Modelling and Environmental Health Research Group, CSIR, P0 Box 395, Pretoria 0001 ,

South Africa

\section{DATES:}

Received: 05 Apr. 2012

Revised: 13 Sep. 2012

Accepted: 14 Sep. 2012

\section{KEYWORDS:}

UV index; sun awareness; skin cancer prevention; personal strategies; personal monitors

\section{HOW TO CITE:}

Wright CY, Albers PN. Comparison of two personal ultraviolet index monitors for sun awareness in South Africa. S Afr J Sci. 2013;109(1/2), Art \#0014, 4 pages. http://dx.doi. org/10.1590/sajs.2013/0014

(C) 2013. The Authors.

Published under a Creative Commons Attribution Licence.
Exposure to solar ultraviolet (UV) radiation is known to have both adverse and beneficial consequences for human health. Sunburn and skin cancer are probably the most well-known acute and chronic adverse health impacts. These themes have recently been discussed in the media for the general public; consequently interest in sun protection is growing. The promotion of the use of practical personal strategies to reduce adverse health risks, such as healthy sun behaviour, sun protection mechanisms and solar ultraviolet radiation awareness tools, is increasing. One such tool is the personal UV index (UVI) monitor, promoted commercially as a viable tool for sun awareness; however, such instruments have not been scientifically evaluated in a South African context. Here, two different types of personal UVI monitors, commercially available in South Africa, were compared with a research-grade UVB biometer for a continuous 7-h period on 02 March 2012 in Pretoria. One of the two personal UVI monitors showed reasonable agreement with the UVB biometer, whereas the other monitor overestimated UVI by up to 4 UVI units. When comparing two identical products manufactured by the same company, one monitor overestimated UVI twofold, suggesting inter-instrument variability may be a concern. Commercially available, personal UVI monitors should be used with caution as a public health tool for sun awareness in South Africa.

\section{Introduction}

Exposure to solar UV radiation is known to have adverse and beneficial consequences for human health. ${ }^{1}$ Beneficial effects include sufficient production of vitamin $D$ and a feeling of well-being. ${ }^{2}$ Adverse effects include those on the skin, eyes and immune system, with skin cancers and cortical cataracts being the most common outcomes. ${ }^{1}$ The most effective preventive measures against the adverse effects of excess sun exposure include safe sun protection practices. However, raising awareness does not necessarily result in positive attitudinal and behavioural changes. ${ }^{3,4}$ Sustained uptake of behavioural changes is a long-term endeavour and has proved successful in parts of Australia where SunSmart public health programmes have been in existence for more than 20 years; skin cancer rates have decreased in these areas.,

Several tools, practices and strategies have been developed to educate the public about the harmful effects of solar UV radiation exposure, especially sunburn. Such education may focus on disease prevention, early detection and treatment and raising awareness about the solar UV radiation environment and healthy sun behaviour. The World Health Organization INTERSUN programme provides guidance about effective sun awareness programmes and encourages countries to reduce UV-induced health risks through coordinated efforts. ${ }^{7}$ The US SunWise programme is one such example of an environmental and health education programme that aims to teach children and their caregivers how to protect themselves from overexposure to the sun.

Some countries maintain a solar UV radiation monitoring network which provides an accurate forecast of the intensity of solar UV radiation in the form of the UV index (UVI) ranging from 1 to $11+.^{8}$ The UVI is forecast daily in some countries, such as in the USA and Australia, and is broadcast with the general weather reports. Behavioural response messages can be added to the UVI bands, such as the message from the Cancer Society of New Zealand for UVI values of 8 to 10 - "Seek shade. Slip, slap, slop and wrap. Re-apply sunscreen regularly". ${ }^{9}$

A real-time, UVI display, manufactured to be research-grade and regularly calibrated, is a useful tool in public places where personal sun exposure can be high (http://www.niwa.co.nz/our-services/online-services/uv-andozone/uvi-display). For example, at a public swimming pool the display indicates UVI readings throughout the day and even changes when a cloud passes overhead. Personal UVI monitors are available commercially. These realtime, visual displays may serve as a reminder for an appropriate behavioural response and to educate people about the patterns of and factors influencing ambient solar UV radiation. However, such monitors are not always accurate or reliable,$^{10}$ and they have not been validated as a public health tool in South Africa. Only a few studies have considered personal sun exposure patterns, ${ }^{11}$ anatomical distribution of solar UV radiation ${ }^{12}$ and sun protection knowledge, attitudes, behaviour and awareness in this country. ${ }^{13}$

Non-scientific, personal UVI monitors are commercially available in South Africa. These include, among others, watches, weather stations, purpose-built UVI display stations and portable dosimeters. Previous research has shown significant discrepancies between commercial and scientific solar UV radiation measuring instruments. ${ }^{10}$ Here, preliminary research was carried out to compare personal UVI instruments that are commercially available in South Africa with a research-grade UV biometer to determine the trustworthiness of the commercial products as sun awareness tools.

\section{Tools and methods}

Several retail outlet stores were searched for personal UVI instruments. The purchased instruments were chosen because they were reasonably priced, readily available and easy to operate. Two types of instruments were employed for physical solar UV radiation measurements. 
Two inexpensive, personal UVI monitors (identical monitors, same brand, name withheld) were purchased from a South African retail store. A reasonably priced UVI display station was bought from an online company (name withheld) that readily ships products to South Africa. These two commercially available products were calibrated against a research-grade Solar Light 501 UVB biometer located at the South African Weather Service (SAWS) in Pretoria (2548'34.12" S; $28^{\circ} 15^{\prime} 22.34^{\prime \prime}$ E). SAWS maintains a routine programme for monitoring erythemally weighted, solar UVB radiation at Cape Town, Cape Point, Durban, Pretoria, Port Elizabeth and De Aar. The main purpose of the solar UVB biometer network is to create public awareness and to provide real-time information regarding the hazard of excess exposure to biologically active solar UVB radiation. Calibration took place on a mostly clear-sky day, i.e. some light cumulus cloud appeared during the day but never obstructed the solar disk (date of calibration was 02 March 2012). Full specifications of the instruments are given in Table 1.

Table 1: Specifications of instruments used in this study for the measurement of solar UV radiation

\begin{tabular}{llll}
\hline \hline & UVI personal monitor & UVI display station & UVB biometer \\
\hline \hline Unit dimensions & $80 \times 43 \times 20 \mathrm{~mm}$ & $10 \mathrm{~cm}$ radius & $14 \times 15 \mathrm{~cm}$ \\
\hline Unit weight & $78 \mathrm{~g}$ without battery & $437 \mathrm{~g}$ & $900 \mathrm{~g}$ \\
\hline Measurement range & $1-25 \mathrm{UVI}$ & $1-11+\mathrm{UVI}$ & $\begin{array}{l}1-10 \mathrm{MED} / \mathrm{h}\left(1 \mathrm{MED}=210 \mathrm{~J} / \mathrm{m}^{2}\right. \\
\left.\text { or } 583 \mathrm{~W} / \mathrm{m}^{2}\right)\end{array}$ \\
\hline Operating temperature & $0-60^{\circ} \mathrm{C}$ & Not given & -40 to $+50^{\circ} \mathrm{C}$ \\
\hline Water resistance & Splash resistant & Splash, rain and snow resistant & $\begin{array}{l}\text { Waterproof and can be used under } \\
\text { water to a maximum depth of } 5 \mathrm{~m}\end{array}$ \\
\hline Power & $1 \times$ CR2032 battery & 3 AA batteries & \begin{tabular}{l} 
AC power \\
\hline Clock
\end{tabular} \\
\hline Sensor & $12-$ or $24-h$ format & None & $\begin{array}{l}\text { Set according to time of computer } \\
\text { linked to data logger }\end{array}$ \\
\hline
\end{tabular}

UVI, ultraviolet index; MED, minimal erythemal dose

All instruments were situated in a non-shaded area on a horizontal and level plane within half a metre of each other on the roof of the SAWS building. Measurements were recorded half-hourly from 10:00 to 16:00, manually for the personal UVI monitors and UVI display station and by the data logger of the biometer. The biometer measurements were recorded in minimal erythemal dose (MED) units $\left(1 \mathrm{MED}=210 \mathrm{~J} / \mathrm{m}^{2}\right)$. These units were later converted to half-hourly UVI values by dividing the MED value by 1800 for the number of seconds in half an hour and then multiplying by 40 , the standard coefficient for calculating UVI. ${ }^{14}$ Thus the measurements of all three instruments were compared in UVI.

The personal UVI monitors (two monitors, same brand) were also compared with each other over 18 days (10-27 May 2011); measurements were not taken on some days because of cloud cover). UVI readings were taken manually on the hour as often as possible between 09:00 and 16:00. The monitors were pointed towards the sun, as recommended by the manufacturer, and were set to measure the UVI within $15 \mathrm{~s}$ of each other. Linear regression was applied to the two sets of UVI measurements to ascertain inter-instrument variability.

\section{Results}

Figure 1 shows the half-hourly UVI readings made by the two personal UVI monitors (UVI_1 and UVI_2), the UVI display station and the SAWS biometer. The SAWS biometer UVI readings show the typical convex curve with UVI increasing towards midday and decreasing towards sunset.

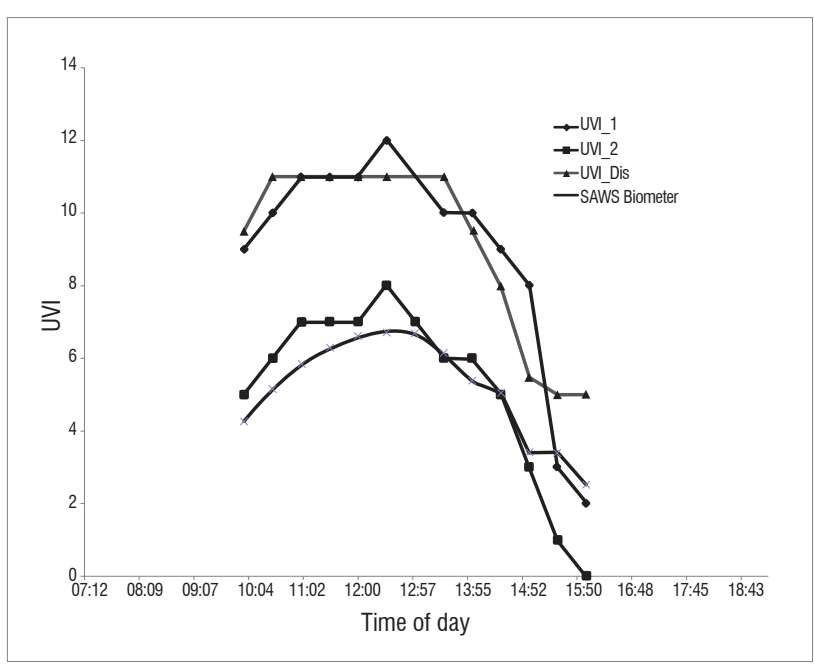

Figure 1: Diurnal pattern in the half-hourly readings of the UV index (UVI) made by two personal UVI monitors (UVI_1 and UVI_2), a UVI display station (UVI Dis) and the biometer of the South African Weather Service (SAWS Biometer) on a clear-sky day (02 March 2012) in Pretoria. 
Measurements from UVI 2 agreed most closely with those of the SAWS biometer, with a linear fit of $y=1.0503 x$ and an $R^{2}=0.7673$ (Figure 2). The measurements of UVI 1 and the UVI display station did not agree as closely with the SAWS biometer data, with linear fits of $y=1.7508 x$ $\left(R^{2}=0.7853\right)$ and $y=1.7639 x\left(R^{2}=0.8347\right)$, respectively (Figure 2).

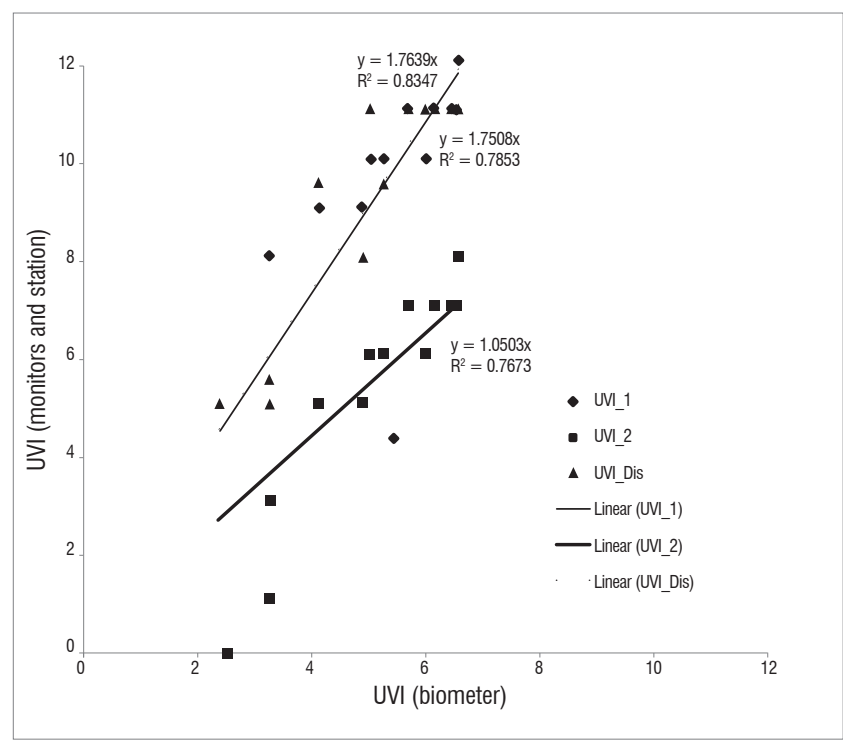

Figure 2: Correlation between readings of the UV index (UVI) made by two personal UVI monitors (UVI_1 and UVI_2) and a UVI display station (UVI_Dis) and the biometer of the South African Weather Service.

These results indicate that UVI_1 and the UVI display station overestimated solar UV radiation by an average of 3.8 and $4.0 \mathrm{UVI}$, respectively. From a personal use and public health perspective, overestimation of UVI by a personal monitor is less worrying than underestimation of UVI, which may lead to excess sun exposure when the individual assumes that UVI levels are lower than they are in reality. However, as shown in Figure 3, UVI 1 overestimated UVI by approximately twofold compared to UVI 2 , despite being identical products made by the same company. Therefore, instrument inconsistency remains a concern.

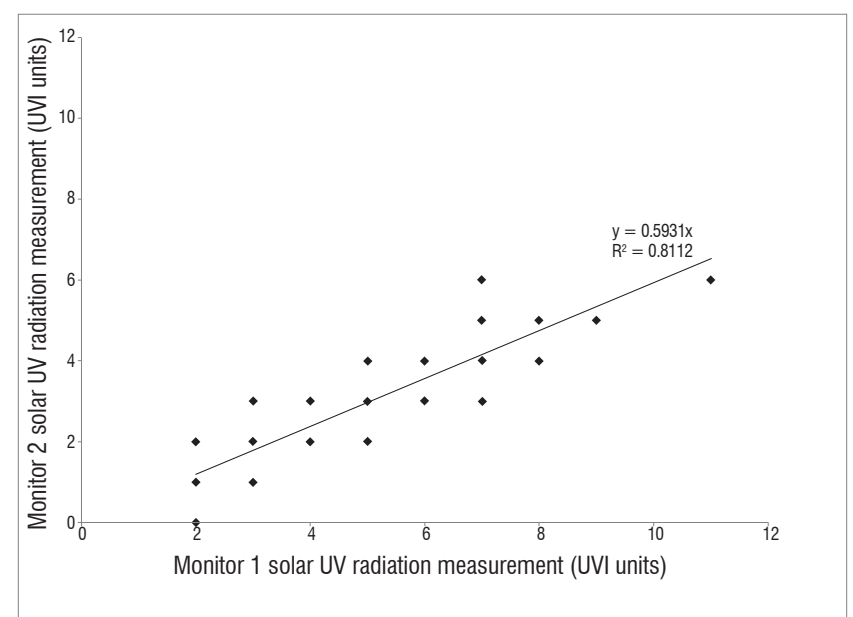

Figure 3: Correlation between UV index (UVI) readings measured by two personal UVI monitors on 18 days in May 2011.

\section{Discussion}

Only one of the personal UVI monitors accurately measured the correct UVI reading as measured by a research-grade instrument. A similar finding was made by de Paula Corrêa et al. ${ }^{10}$ in their study comparing UVI measurements performed by research-grade and consumer-product instruments. They found most consumer-product instruments showed large discrepancies in UVI measurements compared to spectrometer data. It is important to note that comparison of research-grade and commercially available UVI instruments entails comparing two different but related quantities: the horizontal hemispheric solar UV radiation incident on the UV biometer versus the limited solid angle solar UV radiation incident on the personal UVI monitors. ${ }^{10}$ One would expect some differences, naturally occurring, between UVI measurements made by the personal UVI monitors and the UV biometer, but differences larger than $50 \%$ suggest reason for concern. Overestimation of UVI levels is less of a public health concern than underestimation of UVI levels. Additional research in the form of a full research study should be carried out to verify these preliminary results among as many commercially available personal UVI monitors as possible.

An alternative to the use of personal UVI monitors is a forecast of the daily midday UVI values. However, this practice is contested as a public health too ${ }^{9}$ because the predicted UVI midday maximum may not usually change for several days or weeks during summer, unless cloud cover is included in the algorithm. Broadcasting companies are reluctant to report the same UVI value daily for long periods ${ }^{14,15}$ and even if the public understand what the UVI means, hearing the same UVI value given daily may lead to a non-behavioural response. Another alternative may be to always include cloud cover in UVI forecasting calculations and to give mid-morning, midday and mid-afternoon UVI values to the public to show diurnal change in UVI levels and also to indicate suitable periods for outdoor activities. To date, no study has been undertaken in South Africa to ascertain whether the public understands what the UVI describes and how sun protection options may be linked with UVI values.

\section{Conclusions}

For South Africans knowledgeable about the risks of excess sun exposure and who want to protect themselves by using commercially available UVI monitors, there is a risk that the products they acquire are not reliable or trustworthy. Hence, it is important to perform additional research analyses to assess a larger set of commercial UVI instruments during different seasons and at different altitudes, among other factors, in South Africa.

\section{Acknowledgements}

We wish to acknowledge G. Coetzee and K. Ncongwane for provision of SAWS data, CANSA for relevant information, the CSIR for funding, N. Phala for data preparation and M. Norval and R. Garland for helpful discussion.

\section{Authors' contributions}

C.Y.W. conceptualised the project, performed some of the experiments and drafted the manuscript. P.N.A. performed some of the experiments and assisted in writing the manuscript. 


\section{References}

1. Norval M, Lucas RM, Cullen AP, De Gruijl FR, Longstreth J, Takizawa $Y$ et al. The human health effects of ozone depletion and interactions with climate change. Photochem Photobiol Sci. 2011;10:199-225. http://dx.doi. org/10.1039/c0pp90044c

2. De Gruijl FR. Sufficient vitamin D from casual sun exposure? Photochem Photobiol. 2011;87:598-601. http://dx.doi.org/10.1111/j.17511097.2011.00918.x

3. Borland R, Hill D, Noy S. Being sunsmart: Changes in community awareness and reported behaviour following a primary prevention program for skin cancer control. Behav Change. 1990;7(3):126-135.

4. Santiago-Rivas M, Velicer WF, Redding CA, Prochaska JO, Paiva AL. Cluster subtypes within the precontemplation stage of change for sun protection behaviour. Psychol Health Med. 2011;17(3):311-322. http://dx.doi.org/10. 1080/13548506.2011.630401

5. Montague M, Borland R, Sinclair C. Slip! Slop! Slap! and SunSmart 1980 to 2000: Skin cancer control and 20 years of population based campaigning. Health Educ Behav. 2001;28(3):290-305. http://dx.doi. org/10.1177/109019810102800304

6. Cancer Council Victoria. Skin cancer prevention: A blue chip investment in Victoria. Melbourne: Cancer Council Victoria, 2008; p. 1-28.

7. World Health Organization (WHO). INTERSUN: The global UV project - A guide and compendium. Geneva: Radiation and Environmental Health Unit, Protection of the Human Environment, WHO; 2003.

8. World Health Organization (WHO). Global solar UV index: A practical guide. A joint recommendation of the WHO, WMO, UNEP and ICNIRP. Geneva: WHO; 2002
9. Galtry J. The ultraviolet index: Health promotion tool or "poisoned chalice"? NIWA UV Workshop; 2010 May 7-9; Queenstown, New Zealand. Lauder: National Institute of Water and Atmospheric Research; 2010. p. 1-4.

10. De Paula Corrêa M, Godin-Beekmann S, Haeffelin M, Brogniez C, Verschaeve F, Saiag P, et al. Comparison between UV index measurements performed by research-grade and consumer-products instruments. Photochem Photobiol Sci. 2010;9:459-463. http://dx.doi.org/10.1039/b9pp00179d

11. Guy C, Diab R, Martincigh BS. Ultraviolet radiation exposure of children and adolescents in Durban, South Africa. Photochem Photobiol. 2003;77(3):265-270. http://dx.doi.org/10.1562/0031-8655(2003)077<0265:UREOCA > 2.0.C0;2

12. Wright C, Diab R, Martincigh BS. Anatomical distribution of ultraviolet solar radiation. S Afr J Sci. 2004;100:498-500.

13. Wright C, Albers P. Sun-related knowledge, attitudes and behaviours among South Africans: Pilot study results. 27th Annual Conference of the South African Society for Atmospheric Sciences; 2011 Sep 22-23; Hartebeespoort, South Africa. Pretoria: South African Society for Atmospheric Science; 2011. p. 1-4.

14. Bulliard J-L, Reeder Al. Getting the message across: Sun protection information in media weather reports in New Zealand. N Z Med J. 2001;114(1126):67-70.

15. Kime HN, Reeder Al. Sun protection information in summer weather reports: Perceptions and practices. Dunedin: Social and Behavioural Research in Cancer Unit, Department of Preventive and Social Medicine, Dunedin School of Medicine; 2002 